\title{
Branched polyethylenimine-grafted-carboxymethyl chitosan copolymer enhances the delivery of pDNA or siRNA in vitro and in vivo
}

This article was published in the following Dove Press journal:

International Journal of Nanomedicine

25 September 2013

Number of times this article has been viewed

\author{
Seong-Cheol Park* \\ Joung-Pyo Nam* \\ Young-Min Kim* \\ Jun-Ho Kim \\ Jae-Woon Nah \\ Mi-Kyeong Jang
}

Biomedical Polymer Laboratory, Department of Polymer Science and Engineering, Sunchon National University, Suncheon, Republic of Korea

*These authors contributed equally to this work
Correspondence: Jae-Woon Nah Sunchon National University, 255 Jungangno, Suncheon, Jellanamdo, 540-950, Republic of Korea

$\mathrm{Tel}+82617503566$

Fax +82 6I 7505423

Email jwnah@sunchon.ac.kr

\section{Mi-Kyeong Jang}

Sunchon National University, 255 Jungangno, Suncheon, Jellanamdo, 540-950, Republic of Korea

$\mathrm{Tel}+82617503567$

Fax+826I 7505423

Email jmk8856@sunchon.ac.kr

\begin{abstract}
To generate a good carrier for gene transfection, O-carboxymethyl chitosan-graftbranched polyethylenimine (OCMPEI) copolymers were synthesized by increasing the weight percentage of branched polyethylenimine conjugated to the carboxyl groups of O-carboxymethyl chitosan. These spherical polyplexes with plasmid deoxyribonucleic acid (pDNA) or small interfering ribonucleic acid (siRNA) had diameters of $\sim 200-300 \mathrm{~nm}$ or $\sim 10-25 \mathrm{~nm}$, respectively, and displayed significant transfection efficiency in normal and tumor cells. In particular, expression of green fluorescent protein (GFP) following pDNA transfection was effectively suppressed by delivery of GFP-specific siRNA with the same copolymer. The optimized copolymer and polyplexes were nontoxic in vitro and in vivo. The use of endocytosis inhibitors to investigate the mechanisms of transfection of the polyplexes suggested the involvement of macropinocytosis. An in vivo study in mice showed excellent GFP expression in the lung, kidney, and liver. The results demonstrated that the OCMPEI copolymer prepared in this study is a promising carrier for in vitro and in vivo gene delivery applications.
\end{abstract}

Keywords: chitosan, branched polyethylenimine, gene transfection, cytotoxicity, endocytosis

\section{Introduction}

Gene therapy has been regarded to show promise for curing serious diseases, such as cancer, immune deficiency disorders such as acquired immune deficiency syndrome, cystic fibrosis, heart disease, diabetes, and hemophilia. Viral gene vectors remain the most popular vehicle for gene therapy in clinical trials owing to their high transfection efficiency, although their high immunogenic and poor circulatory properties restrict their widespread use. In contrast to viral vectors, nonviral gene delivery vectors have attracted great attention because of their biosafety and easy modification. ${ }^{1-5}$ They have been divided into two types: liposome-based gene carriers (lipoplexes) and polymerbased gene carriers (polyplexes). ${ }^{6}$ Although lipoplexes often showed high transgene expression, their limited use resulted from their nonspecific membrane activity. ${ }^{7-9}$ A number of cationic polymers have been developed because they can interact with the anionic phosphate groups of naked DNA or RNA, generating compact complexes. ${ }^{7-10}$ Among these, polyethyleneimine (PEI) and chitosan have been widely studied, given their attractive properties for drug delivery. ${ }^{11-13}$

PEI is a promising synthetic vector for gene delivery because its high cationicity allows it to condense and protect nucleic acids (plasmid DNA [pDNA] or small interfering RNA [siRNA]) from nuclease digestion, as well as enabling endosomal escape via the "proton sponge" effect. ${ }^{14,15}$ The transfection efficiencies and toxicities of PEIs differ in a mass-dependent or structure-dependent manner, and it is difficult 
to define the relationships between theses parameters. ${ }^{16,17}$ Therefore, the application of PEI is limited by its high toxicity and proinflammatory effects. ${ }^{18}$

The natural polysaccharide chitosan has been recognized as a safer carrier, given its biodegradability, lack of toxicity, limited immunogenicity, and biocompatibility. ${ }^{19,20}$ Above all, the polycationic character of chitosan has attracted many researchers in the field of gene therapy to use chitosan and its derivatives for applications as diverse as drug delivery, ${ }^{19-21}$ tissue engineering, ${ }^{22-24}$ antibiotic delivery, ${ }^{25,26}$ and the preparation of chitosan-based biomaterials..$^{27,28}$

Several approaches that enable the chemical combination of chitosan and PEI to promote gene delivery were reported recently. ${ }^{29-34}$ In the present study, O-carboxymethyl chitosangraft-branched polyethylenimine (OCMPEI) copolymers with various ratios of branched polyethylenimine (bPEI) were synthesized, and their suitability for the delivery of pDNA or siRNA was evaluated. The copolymers were investigated with respect to their biophysical characters, capacity to condense with nucleic acids, cytotoxicity, cellular uptake, and transfection efficiency. Moreover, both the in vitro gene silencing efficacy of OCMPEI-siRNA polyplexes and in vivo gene expression of OCMPEI/pDNA polyplexes were evaluated in cancer cells and mice, respectively. Inhibitors of endocytosis were used to investigate the cellular delivery mechanism of polyplexes.

\section{Materials and methods Materials}

Plasmid DNA (pGL3 vector) that encodes a modified firefly luciferase and a Luciferase Assay System were purchased from Promega (Madison, WI, USA). Plasmid DNA (pEGFPC1) that encodes green fluorescent protein (GFP) was obtained from BD Biosciences (Palo Alto, CA, USA). The siRNA for targeted silencing of GFP (siGFP) and scrambled siGFP RNA were purchased from Bioneer Co (Daejeon, Republic of Korea). The BCA Protein Assay Kit was from Pierce Chemical (Rockford, IL, USA). Water soluble chitosan (molecular weight, 12,000 Da; deacetylation degree, 97.0\%) was provided by Chittolife Co, Ltd (Pyeongtaek, Republic of Korea). Branched PEI (25 kDa), 3-(4,5-dimethylthiazol2-yl)-2,5-diphenyltetrazolium bromide (MTT), 1-ethyl-3(30dimethylaminopropyl) carbodiimide hydrochloride (EDC), N-hydroxysuccinimide (NHS), and other chemicals were purchased from Sigma-Aldrich (St Louis, MO, USA).

\section{Preparation of OCMCh}

Low molecular weight water soluble chitosan (LMWSC) was prepared as described previously. ${ }^{35}$ O-carboxymethyl chitosan (OCMCh) was synthesized as described previously, with some modification. ${ }^{36}$ Briefly, 2 g of LMWSC was immersed in $25 \mathrm{~mL}$ of $50 \%(\mathrm{w} / \mathrm{v}) \mathrm{NaOH}$ solution and alkalized for 24 hours. The alkalized LMWSC was filtered and then transferred into a flask, after which $5 \mathrm{~g}$ of monochloroacetic acid in isopropanol was added in a dropwise manner for 20 minutes. This flask was allowed to react for a further 8 hours at room temperature (RT). The reactants were filtered to remove the solvent, and the filtrates were then dissolved in $100 \mathrm{~mL}$ of water, thereafter the $\mathrm{pH}$ was adjusted to 7.0 using $2 \mathrm{~N} \mathrm{HCl}$. The product was precipitated by ethanol and the precipitates were harvested by filtration. Residual ethanol was removed by vacuum drying.

\section{Phthaloylation of OCMCh}

One gram of phthalic anhydride was dissolved in $10 \mathrm{~mL}$ of $\mathrm{N}$,N-dimethylformamide containing $5 \%(\mathrm{v} / \mathrm{v})$ water, followed by the addition of $0.36 \mathrm{~g}$ of OCMCh. The mixture was heated under nitrogen at $120^{\circ} \mathrm{C}$ while gently stirring overnight. After reaction, the phthaloylated chitosan solution was cooled at RT and then left in ice-cold water. The precipitates were harvested by filtration and washed with methanol. Residual methanol was removed by vacuum-drying. This amine protection was analyzed by using ${ }^{1} \mathrm{H}$ nuclear magnetic resonance ( ${ }^{1} \mathrm{H}-\mathrm{NMR}$; Bruker, Karlsruhe, Germany; $\left.400 \mathrm{MHz}\right)$ and Fourier transform infrared spectroscopy.

\section{Preparation of phthaloylated OCMPEI}

Phthaloylated OCMPEI copolymers with different degrees of grafting of $25 \mathrm{kDa}$ bPEI to carboxyl groups of the phthaloylated OCMCh backbone were generated by chemical synthesis. Briefly, phthaloylated OCMCh solution was activated by the addition of EDC and NHS at 1:2:2 molar ratios in $50 \mathrm{mM}$ 4-(2-hydroxyethyl)-1-piperazineethanesulfonic acid ( $\mathrm{pH} 7.0)$ buffer containing $40 \%(\mathrm{v} / \mathrm{v})$ dimethyl sulfoxide for 1 hour at RT, after which a solution of $5 \%, 10 \%, 15 \%$, or $20 \%$ bPEI (weight \%) was added, gently stirred, and then incubated for 24 hours at RT. After reaction, the solution of phthaloylated OCMPEI was dialyzed against distilled water for 2 days; the resulting solution was freeze-dried.

\section{Deprotection of phthaloylated OCMPEI}

Phthaloylated OCMPEI $(200 \mathrm{mg})$ was mixed in $50 \mathrm{~mL}$ distilled water with $30 \mathrm{~mL}$ of hydrazine monohydrate using gentle magnetic stirring overnight at $100^{\circ} \mathrm{C}$; the mixture solution was then poured into $500 \mathrm{~mL}$ of ice water. Excess hydrazine monohydrate in the mixture solution was removed by evaporating using a rotary evaporator. The final product 
was lyophilized under a vacuum to obtain the deprotected OCMPEI. Synthesis of copolymers was estimated by measuring ${ }^{1} \mathrm{H}-\mathrm{NMR}$ (Bruker, $400 \mathrm{MHz}, \mathrm{D}_{2} \mathrm{O}$ ).

\section{Animals for in vivo gene transfection studies}

Six-week-old male slc:ICR mice $(25 \pm 2$ g, SLC Japan Inc, Shizuoka, Japan) were used to investigate GFP gene expression in vivo. Mice were housed separately ( 2 animals per cage) under conditions of controlled temperature $\left(23^{\circ} \mathrm{C} \pm 2{ }^{\circ} \mathrm{C}\right)$, humidity $(50 \% \pm 15 \%)$, and lighting (lights on from 8 am to $8 \mathrm{pm}$, illuminance of 150 300 Lux). All animal studies were approved by the Animal Care Committee of Sunchon National University (SCNU_IACUC-2013-6), and all animal care was in accordance with the guidelines of the Korea Council on Animal Care.

\section{pDNA/siRNA gel retardation assay}

pEGFP-C1 plasmid was transformed into Escherichia coli JM109, and the cells were propagated in Luria-Bertani (LB) media at $37^{\circ} \mathrm{C}$ overnight. The plasmid was purified using a plasmid extraction kit (Exprep ${ }^{\mathrm{TM}}$ Quick, GeneAll Biotechnology Co, Seoul, Republic of Korea) according to the manufacturer's protocol. The purity of the pDNA was assessed by determining the OD260/OD280 absorbance ratio. The GFP siRNA (sense: 5'-GCAUCAAGGUGAACUUCAAdTdT-3'; antisense: 5'-UUGAAGUUCACCUUGAUGCdTdT-3'), and scrambled siRNA (sense: 5'-CUACGCCACCAAUUUCGUdTdT-3'; antisense: 5'-ACGAAAUUGGUGGCGUAGGdTdT-3') were obtained from Bioneer Co (Daejeon, Republic of Korea). They were stored at $-20^{\circ} \mathrm{C}$ until use.

Both pDNA and siRNA polyplexes were prepared by mixing 400-500 ng of pDNA or $500 \mathrm{ng}$ of siRNA and different amounts of OCMPEIs in PBS (phosphate-buffered saline; $\mathrm{pH}$ 7.4) at the appropriate concentrations to yield different weight ratios. The products were further incubated for 30 minutes at $25^{\circ} \mathrm{C}$. All of the polyplexes were electrophoresed $(100 \mathrm{~V}, 50$ minutes) in $0.8 \%$ (w/v) agarose gel, stained with ethidium bromide (EtBr) and visualized on an UV transilluminator using a gel documentation system (Bio-Rad Laboratories, Hercules, CA, USA).

\section{DNA protection and release assay}

The capacity of OCMPEI to protect DNA from degradation was assessed by adding DNase after the formation of polyplexes. Briefly, $1.5 \mu \mathrm{L}$ of RNase-Free DNase I ( $1 \mathrm{U} / \mu \mathrm{L}$ in buffer containing $100 \mathrm{mM}$ Tris, $25 \mathrm{mM} \mathrm{MgCl}_{2}, 5 \mathrm{mM} \mathrm{CaCl}_{2}$ ) was incubated with the indicated polyplexes for 1 hour at $37^{\circ} \mathrm{C}$. After incubation, $5 \mu \mathrm{L}$ of EDTA (ethylenediaminetetraacetic acid) solution ( $100 \mathrm{mM})$ was added and the mixture was incubated at $75^{\circ} \mathrm{C}$ for 10 minutes to inactivate DNase. The samples were electrophoresed through a $0.8 \%$ agarose gel and stained using EtBr.

The pDNA were released from polyplexes by treatment with heparin. Briefly, OCMPEI/pDNA complexes were prepared at various weight ratios, ranging from 1 to 16 in PBS ( $\mathrm{pH} 7.4$ ) and incubated for 30 minutes at RT before adding heparin (10 U). The samples were incubated for 20 minutes and electrophoresed in $0.8 \%$ agarose gel. Gels stained with EtBr were visualized on an UV transilluminator.

\section{Measurement of the sizes of polyplexes}

The particle sizes of polyplexes (OCMPEI/pDNA complex) were measured using a dynamic light scattering (DLS) instrument (ELS-8000 electrophoretic LS spectrophotometer, Otsuka Electronics, Osaka, Japan), fitted with a $\mathrm{He}-\mathrm{Ne}$ laser at a fixed scattering angle of $90^{\circ}$. For each sample, $10 \mu \mathrm{g}$ of pEGFP-C1 was added to $90 \mu \mathrm{L}$ of OCMPEIs at a weight ratio of $1: 16$ in PBS ( $\mathrm{pH} 7.4)$; the mixtures were incubated for 30 minutes at $25^{\circ} \mathrm{C}$, followed by the addition of $300 \mu \mathrm{L}$ PBS.

\section{Morphologies of polyplexes}

Both pDNA and siRNA-containing polyplexes were prepared at an OCMPEI concentration of $0.1 \mathrm{mg} / \mathrm{mL}$. Polyplexes $(6 \mu \mathrm{L})$ were applied to glow-discharged carbon-coated copper grids for 1 minute. The grids were rinsed three times in distilled water and stained with $2 \%(\mathrm{w} / \mathrm{v})$ uranyl acetate. Electron microscopic images were then recorded using an FEI Tecnai G2 transmission electron microscope (Hillsboro, OR, USA) with an accelerating voltage of $200 \mathrm{kV}$ operated in the low-dose mode.

\section{Cell culture}

To examine cell viability and in vitro transfection efficiency, HEK293 (human embryonic kidney 293), HCT119 (colon cancer), U937 (human histiocytic leukemia), LoVo (colon cancer), L929 (mouse connective tissue), and G361 (human Caucasian malignant melanoma) cells obtained from Korean Cell Line Bank (Seoul, Republic of Korea) were cultured in either Dulbecco's Modified Eagle Medium or RPMI-1640 (Roswell Park Memorial Institute 1640) medium. Both media were supplemented with antibiotics $(100 \mathrm{U} / \mathrm{mL}$ penicillin, $100 \mu \mathrm{g} / \mathrm{mL}$ streptomycin, and $10 \mu \mathrm{g} / \mathrm{mL}$ plasmocin) and $10 \%$ fetal calf serum. All cells were grown at $37^{\circ} \mathrm{C}$ in a humidified atmosphere containing $5 \% \mathrm{CO}_{2}$. 


\section{Cytotoxicity and hemolysis}

The cytotoxicity of OCMPEI and OCMPEI-pDNA complexes were evaluated using an MTT (3-(4,5-dimethylthiazol-2-yl)2,5-diphenyltetrazolium bromide) assay to measure cell viability. A total of $5 \times 10^{3}$ cells/well of HEK 293 or L929 cells were seeded into a 96-well plate and incubated for 24 hours. The OCMPEI and OCMPEI-pDNA complexes were diluted in serial with Opti-MEM medium, and then added to each plate and incubated for 24 hours at $37^{\circ} \mathrm{C}$. After the incubation, $10 \mu \mathrm{L}$ of MTT solution $(5 \mathrm{mg} / \mathrm{mL}$ in PBS) was added to each well, and the cells were incubated for another 4 hours at $37^{\circ} \mathrm{C}$. Ten microliters of $5 \mathrm{mg} / \mathrm{mL}$ MTT was added to each well and incubated for an additional 4 hours. The supernatants were aspirated and $100 \mu \mathrm{L}$ of dimethyl sulfoxide was added to the wells in order to dissolve any remaining precipitate. Absorbance was then measured at $570 \mathrm{~nm}$ (optical density) and $670 \mathrm{~nm}$ (subtract background) using a microtiter reader, Finally, the absorbance was measured at wavelength of $570 \mathrm{~nm}$ (optical density) and $670 \mathrm{~nm}$ (subtract background). The relative cell viability (\%) was calculated according to the following equation:

$$
\mathrm{OD} \text { value }=\mathrm{OD}_{560}-\mathrm{OD}_{670}
$$

$$
\begin{aligned}
\text { Relative cell viability }(\%)= & {\left[\left(\mathrm{OD}_{\text {sample }}-\mathrm{OD}_{\text {triton X-100 }}\right) /\right.} \\
& \left.\left(\mathrm{OD}_{\text {control }}-\mathrm{OD}_{\text {triton X-100 }}\right)\right] \\
& \times 100
\end{aligned}
$$

In order to investigate in vitro cytotoxicity of polyplexes in rat red blood cells (rRBCs), hemolysis was assayed with blood collected from rats. Heparinized fresh blood was centrifuged at $800 \mathrm{~g}$ and the collected rRBCs were washed with PBS (pH 7.4) until the supernatant was clear. Polyplexes in PBS were plated and rRBCs were then added to a final concentration of $8 \%(\mathrm{v} / \mathrm{v})$ in a $96-w e l l$ plate. The sample was incubated with mild agitation for 1 hour at $37^{\circ} \mathrm{C}$. The samples were then centrifuged at $800 \mathrm{~g}$ for 10 minutes. The absorbance of the supernatant was measured at $414 \mathrm{~nm}$, each measurement was made in triplicate, and percentage hemolysis was calculated using followed equation:

$$
\begin{aligned}
\% \text { hemolysis }= & {\left[\left(\mathrm{Abs}_{414}\right.\right. \text { in the sample solution }} \\
& \left.-\mathrm{Abs}_{414} \text { in PBS }\right) /\left(\mathrm{Abs}_{414} \text { in } 0.1 \%\right. \\
& \text { Triton-X100- } \left.\left.\mathrm{Abs}_{414} \text { in PBS }\right)\right] \times 100
\end{aligned}
$$

$100 \%$ hemolysis is defined as the absorbance of rRBCs containing $0.1 \%$ Triton X-100 and zero hemolysis consisted of rRBCs alone in PBS.

\section{In vitro transfection}

In vitro transfection of naked DNA (pEGFP-C1, $2 \mu \mathrm{g}$ ) or siRNA $(0.3 \sim 1 \mu \mathrm{g})$, commercial transfection reagents, and OCMCh, bPEI, and OCMPEI with pDNA or siRNA in the absence of serum was performed on various cell lines. The cells were plated in 24-well culture plates at a density of $5 \times 10^{4}$ cells/well and grown in antibiotic-free medium for 24 hours before the treatment. Before transfection, media were removed and the cells were washed with serum-free media, after which the samples in reduced-serum media (Opti-MEM, Life Technologies, Carlsbad, CA, USA) were treated at desired weight ratios into each well. In particular, siRNA was labeled with propidium iodide (PI) dye in order to observe intracellular uptake using a fluorescent microscope. After 4 hours, serum was added to each well of the plate at $10 \%(\mathrm{v} / \mathrm{v})$ and the cells were further cultivated for 12 hours. Then, media were replaced with media containing antibiotic and FBS and the cells were cultivated for an additional $\sim 1-2$ days. Gene transfection was visualized using fluorescence microscopy.

\section{Luciferase assay}

To evaluate the transfection efficiencies of polyplexes with pDNA, pGL3 $(1 \mu \mathrm{g})$ was complexed with OCMCh, bPEI, and OCMPEIs at various weight ratios, and in vitro transfection was performed as described above. After 2 days, the luciferase assay was performed according to the manufacturer's protocols. Relative light units were measured at $570 \mathrm{~nm}$. Protein quantification was determined by the bicinchoninic acid method to normalize relative light unit/protein concentration in the cell extracts. Each transfection experiment was carried out in triplicate and transfection efficiency was expressed as relative light units.

\section{Gene silencing with GFP siRNA}

Gene silencing assays were performed in previously transfected pEGFP-C1 HCT119 cells using either $300 \mu \mathrm{g}$ or $600 \mu \mathrm{g}$ of GFP-specific siRNA or scrambled siRNA. After 1 or 2 days, downregulation of GFP expression via transfection of GFP siRNA was investigated by fluorescence microscopy and Western blotting analysis. The proteins extracted from cells were separated on a $12 \%$ SDS-PAGE gel, and Western blot analysis was performed using antibodies specific to GFP (1:1,000, ab290; Abcam, Cambridge, UK) and glyceraldehyde 3-phosphate dehydrogenase $(1: 1,000$, ab9484; Abcam) using the standard method. 


\section{In vivo transfection and expression of GFP}

After mixing pEGFP $(30 \mu \mathrm{g})$ with 15\% OCMPEI at a weight ratio of 32 , the polyplexes were incubated for 30 minutes at $25^{\circ} \mathrm{C}$. The final volume was adjusted to $100 \mu \mathrm{L}$ using PBS, and the polyplexes were injected into the tail veins of ICR mice (6-week-old males, $25 \pm 2 \mathrm{~g}$ ). The experiment was performed independently in triplicate. The mice were fed a normal diet for 5 days, and were then anesthetized to obtain in vivo images. They were then sacrificed and the vital organs were removed and washed with chilled PBS. The organs were also fluorescently imaged using an ImageQuant LAS 4000 instrument (GE Healthcare Bio-Sciences Corp, Piscataway, NJ, USA).

\section{Endocytic mechanism of pDNA/OCMPEI polyplexes}

To investigate whether endocytic pathways participate in the uptake of pDNA-containing polyplexes, the effects of endocytosis inhibitors was investigated in HCT 119 cells. The cells were seeded in 6 -well plates at $1 \times 10^{6}$ cells/well and incubated overnight prior to assay. The cells were then preincubated separately with $10 \mu \mathrm{g} / \mathrm{mL}$ chlorpromazine, $3 \mu \mathrm{g} / \mathrm{mL}$ sodium azide, $8 \mu \mathrm{g} / \mathrm{mL}$ colchicine, and $6 \mu \mathrm{g} / \mathrm{mL}$ indomethacin for 1 hour, after which time the media was replaced with pEGFP-OCMPEI polyplexes containing the endocytic inhibitors mentioned above. After a 4-hour incubation, the media was replaced with fresh media with FBS and antibiotics. The cells were incubated for an additional 24 hours, harvested, and analyzed using a FACSCalibur flow cytometer.

\section{Statistical analysis}

All the data are presented as the mean \pm standard error. The statistical analysis of the results was analyzed by Student's $t$-test. A $P$-value of $<0.05$ was considered to represent a significant difference.

\section{Results and discussion \\ Synthesis and characterization of the OCMPEI copolymer}

The choice of the gene carrier used for nonviral gene delivery or gene therapy is a critical consideration to ensure high transfection efficiency and low cytotoxicity. Although chitosan has received attention as a biodegradable and biocompatible polycationic nonviral vector, its low transfection efficiency has been an obstacle for its application as a gene delivery vector. ${ }^{13}$ Features of chitosan that have limited in vitro or in vivo applications include its ability to bind strongly to nucleic acids, leading to a delay in the release of nucleic acids from endosomes to the cytoplasm. ${ }^{37,38}$ This gradually leads to degradation of the nucleic acids by cytosolic enzymes, ${ }^{39}$ and suggests that a good gene delivery system is essential for a rapid release of the gene of interest from the carrier. Although high molecular weight bPEI is also recognized as a good potential gene carrier, its use has also been limited, owing to its high cytotoxicity. ${ }^{14,15}$ In order to complement these limitations, we synthesized OCMCh-graft-branched PEI (OCMPEI) copolymers which had an increasing amount of bPEI conjugated to the carboxyl groups of OCMCh.

As shown in Figure 1A, the C6-OH position on LMWSC was first modified to a carboxymethyl group by monochloroacetic acid, which generated OCMCh. The free amine group in OCMCh was protected by phthalic anhydride and the phthaloylated-OCMPEI copolymers were synthesized by forming an amide bond between activated carboxyl groups in phthaloylated-OCMCh and bPEI amine groups. OCMPEI with free amine groups was prepared by a deprotecting procedure (Figure 1B). The synthesized OCMCh, 10\% OCMPEI copolymer, and bPEI were analyzed by ${ }^{1} \mathrm{H}-\mathrm{NMR}$ (Figure 2), and characterized as follows: $\mathrm{OCMCh}{ }^{1} \mathrm{H}-\mathrm{NMR}$ $\left(\mathrm{D}_{2} \mathrm{O}, \mathrm{ppm}, \mathrm{TMS}\right) ; \delta=4.9 \mathrm{ppm}(1, \mathrm{CH}$ of $\mathrm{C} 1$ position in OCMCh), $\delta=3.9 \mathrm{ppm}$ (7, $\mathrm{CH}$ of $\mathrm{C} 7$ position OCMCh), $\delta=3.0 \sim 3.8$ ppm $\left(2,3,4,5\right.$, and $6, \mathrm{CH}, \mathrm{CH}_{2}$ in $\mathrm{C} 2, \mathrm{C} 3$, $\mathrm{C} 4, \mathrm{C} 5$, and $\mathrm{C} 6$ position of $\mathrm{OCMCh}$ ) and $\delta=2.3 \sim 2.8 \mathrm{ppm}$ (a, b, c, and d, CH in bPEI). In addition, copolymers with different bPEI weight ratio percentage values increased the characteristic chemical shifts of bPEI according to the amount of bPEI grafted (Figure S1). This suggests that synthesis of the OCMPEI copolymers was successful. The OCMPEI copolymers significantly enhanced the transfection efficiencies of pDNA and siRNA without problematic levels of cytotoxicity.

\section{Characterization of pDNA/OCMPEI polyplexes}

The ability of the OCMPEI copolymers to bind pDNA was determined using an electrophoretic mobility shift assay. Figure $3 \mathrm{~A}$ shows the condensation of DNA with $5 \%, 10 \%$, $15 \%$, and $20 \%$ OCMPEI copolymers in various weight ratios. Whereas free pDNA (Figure 3A, control) showed the distinct bands, which corresponded with the supercoiled, circular, and nicked forms of the plasmid, electrophoretic migration of pDNA complexed with OCMPEI copolymers was dosedependently retarded in grafting ratios ranging from $5 \%$ to 


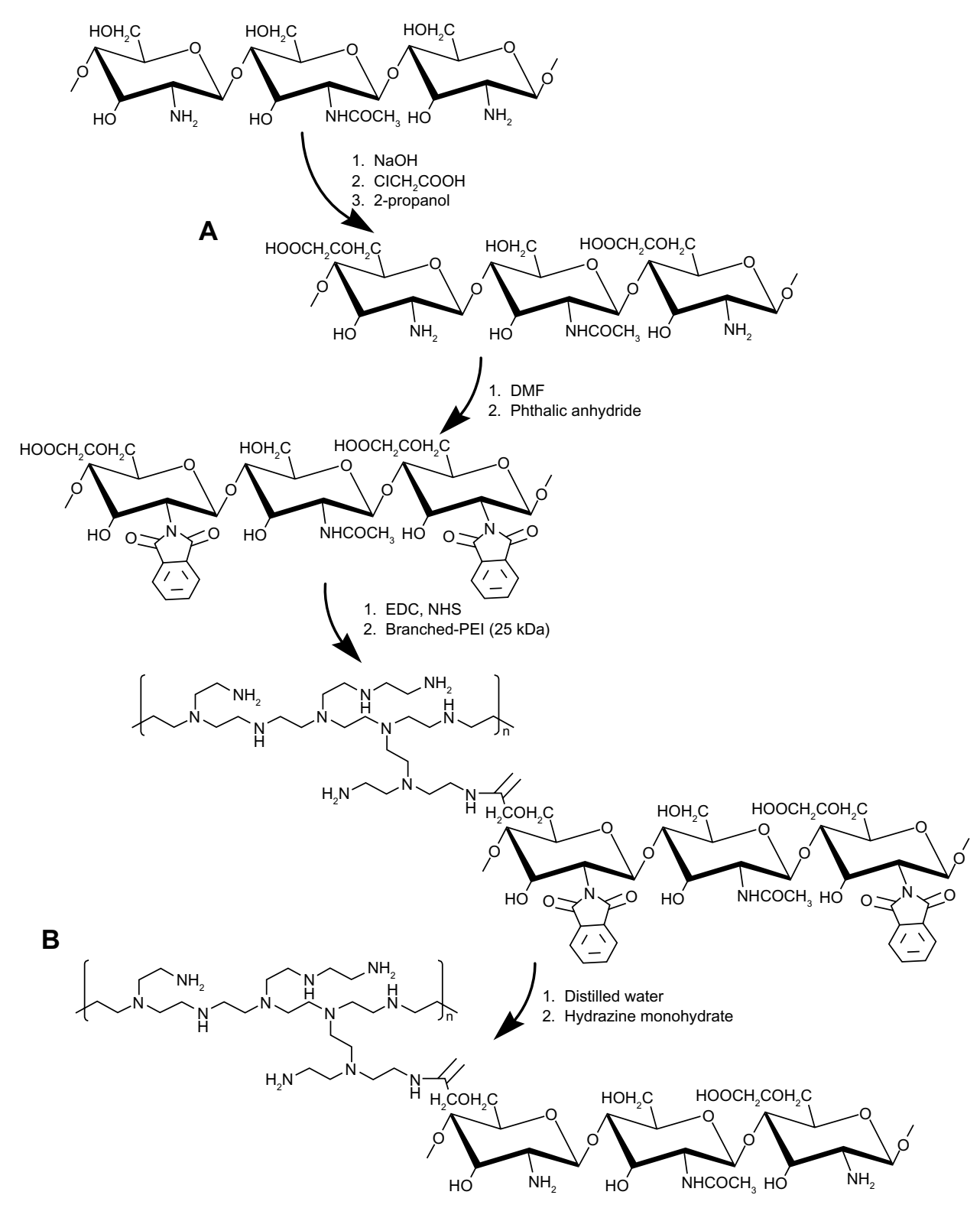

Figure I Proposed reaction scheme for synthesis of OCMPEI copolymer.

Notes: LMWSC was modified to OCMCh $(\mathbf{A})$ by monochloroacetic acid. OCMPEI copolymers $(\mathbf{B})$ were synthesized by a chemically coupling reaction between EDC/NHSactivated carboxyl groups of OCMCh and amine groups of bPEI.

Abbreviations: bPEI, branched polyethylenimine; DMF, dimethylformamide; EDC, I-ethyl-3-(30dimethylaminopropyl) carbodiimide hydrochloride; LMWSC, low molecular weight water soluble chitosan; NHS, N-hydroxysuccinimide; OCMCh, O-carboxymethyl chitosan; OCMPEI, O-carboxymethyl chitosan-graft-branched polyethylenimine.

$15 \%$ due to enhanced positive charge in OCMPEI copolymers. Interestingly, the retardation pattern of $20 \% \mathrm{pDNA} / \mathrm{OCMPEI}$ polyplexes was different from the others, in that the highly and lowly condensed bands appeared together. This result was consistent with size distributions of $20 \%$ OCMPEI, shown in Figure 4A4. We suggest that DNA binding pattern of $20 \%$ OCMPEI is due to its stronger positive charge and DNA forms. For example, because its binding to DNA is very fast upon strong electrostatic interaction, the size of the polyplexes is small and excess polymers are unable to bind with the polyplexes due to repulsive force.
To protect the bound pDNA from digestion with nucleases, polyplexes that were complexed at $\mathrm{w} / \mathrm{w}$ ratios of 1 and 2 were treated with DNase I for 1 hour. As shown in Figure 3B, the complete degradation of naked pDNA and pDNA with $5 \%$ OCMPEI by the enzyme indicated the resistance of pDNA to digestion by nucleases. However, other polyplexes presented the distinguishable protecting ability of bound pDNA from DNase I at a w/w ratio of 2 . If the surface of DNA is surrounded by copolymers, or DNase cleavable sites of DNA are occupied at low concentrations, polymers can protect from DNase attack sufficiently. These results proposed 

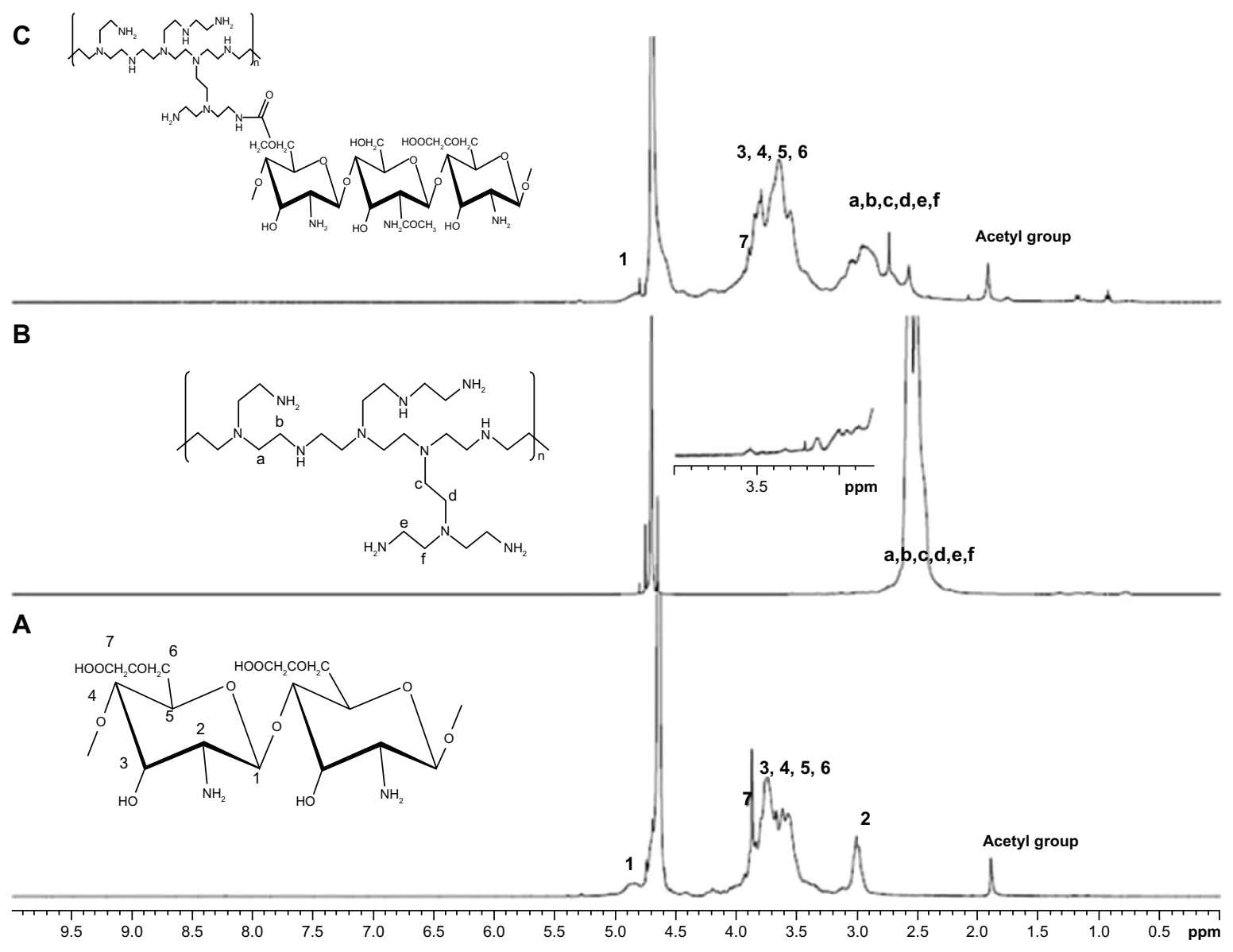

Figure 2 'H-NMR of OCMCh (A), bPEI (B), and OCMPEI (C).

Note: Numbers I-7 and letters a-f indicate peaks of OCMCh and PEI, respectively.

Abbreviations: bPEI, branched polyethylenimine; NMR, nuclear magnetic resonance; OCMCh, O-carboxymethyl chitosan; OCMPEI, O-carboxymethyl chitosan-graftbranched polyethylenimine.

that OCMPEI copolymers, even in low concentration, have the ability to protect the bound pDNA from degradation by nucleases present in blood and other body fluids when pDNA-carrying polyplexes are used in vivo.

Given the importance of effective release of pDNA from polyplexes for efficient transfection, to deliver genes to be expressed within cells, ${ }^{31}$ we confirmed the release of pDNA after incubation with the anionic polysaccharide heparin (Figure 3C). Interestingly, pDNA at all w/w ratios was in the same position with free $\mathrm{pDNA}$, indicating complete release of pDNA from copolymers. This may indicate an easy endosomal escape of pDNA when polyplexes are delivered into cells.

\section{Sizes and morphologies of pDNA-containing polyplexes}

To investigate the size distributions and morphologies of pDNA-containing polyplexes, pDNA was complexed with OCMPEI copolymers at a w/w ratio of $1: 16$, and the polyplexes were analyzed using DLS and transmission electron microscopy (TEM). As shown in Figure 4A, the unimodal sizes of polyplexes with $5 \%, 10 \%$, and $15 \%$ OCMPEI at a w/w ratio of 16 ranged from $\sim 200-300 \mathrm{~nm}$, whereas the average dimodal size of polyplexes with $20 \%$ OCMPEI was $408 \mathrm{~nm}$, which is consistent with the DNA migration pattern of Figure $3 \mathrm{~A}$. The morphologies and sizes of polyplexes were also visualized using TEM (Figure 4B), which revealed them to have a regular spherical shape. The sizes that were estimated using TEM are similar to those estimated using DLS.

\section{Cytotoxicity of the OCMPEI copolymer and pDNA/OCMPEI polyplexes}

An MTT assay was performed on HEK293 cells to assess the in vitro toxicity of OCMPEI copolymers. Assessment of the viability of cells after treatment with various levels of OCMPEIs indicated that free bPEI was more cytotoxic than either OCMCh or OCMPEI copolymers (Figure 5A). Furthermore, we investigated the hemolytic effect of 
A

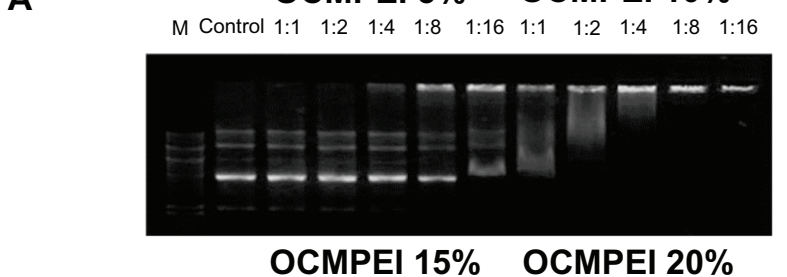
M Control $1: 1 \quad 1: 2 \quad 1: 4 \quad 1: 8 \quad 1: 16 \quad 1: 1 \quad 1_{1: 2} \quad 1: 4 \quad 1: 8 \quad 1: 16$

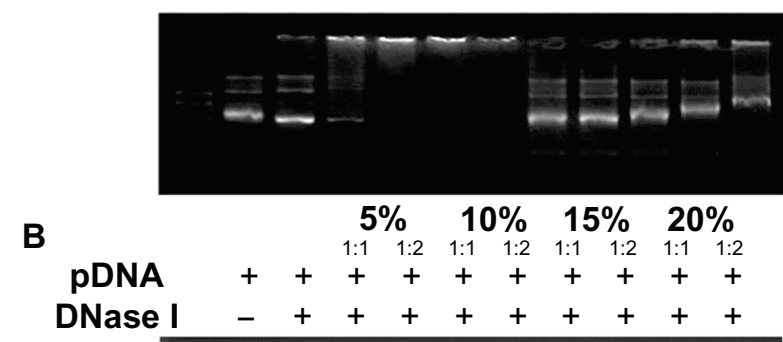

C

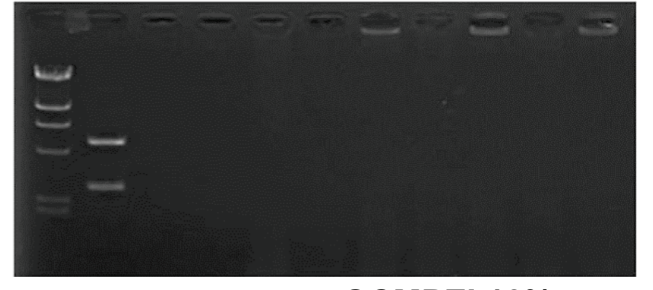

OCMPEI $\mathbf{5} \%$ OCMPEI $\mathbf{1 0} \%$

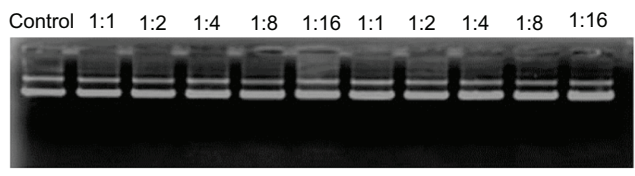

OCMPEI $15 \%$ OCMPEI $20 \%$

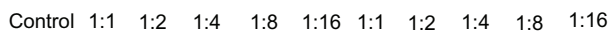

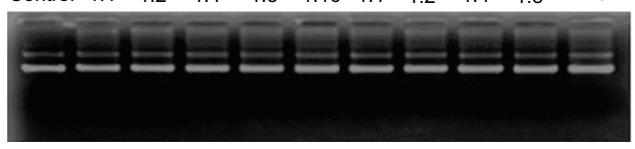

Figure $3 \mathrm{Gel}$ retardation assay of the pDNA/OCMPEI polyplexes.

Notes: (A) Electrophoretic mobility shift assay of pDNA/OCMPEI polyplexes at weight ratios. (B) DNase protection assay of pDNA/OCMPEI polyplexes (w/w: I:I and $\mathrm{I}: 2$ ) when treated with DNase I. (C) DNA-releasing assay from pDNA/OCMPEI polyplexes when treated with heparin.

Abbreviations: DNA, deoxyribonucleic acid; OCMPEI, O-carboxymethyl chitosangraft-branched polyethylenimine; pDNA, plasmid DNA.

pDNA-bPEI, pDNA-OCMCh, and pDNA-OCMPEI complexes on hRBCs (Figure 5B). Whereas the pDNA-PEI complex induced high levels of hemoglobin release from rRBCs, pDNA-OCMCh and pDNA-OCMPEI complexes displayed less than $5 \%$ hemolysis even at higher $\mathrm{w} / \mathrm{w}$ ratios. Both the luciferase assay and fluorescence microscopy showed that the transfection efficiency of the OCMPEI-gene polyplexes depended on the amount of bPEI grafted, with $20 \%$ OCMPEI being more cytotoxic than other copolymers tested. The ability of polymers to bind nucleic acids via electrostatic interaction is generally enhanced by increased cationicity. However, cationic polymers are likely to increase cytotoxicity by impairing membrane functions or damaging membrane structures. This is consistent with the aggregation of polymers and disrupted cell membrane on the cell surface. We found that $10 \%$ and $15 \%$ OCMPEI have an optimum cationicity with good gene transfection and minimum cytotoxicity.

\section{In vitro cell transfection of pDNA/ OCMPEI polyplexes}

The nucleic-acid-carrying ability of OCMPEI copolymers was evaluated by in vitro transfection of pEGFP into HEK293, HCT119, LoVo, L929, and G361 cells (Figure 6). Observation of the pEGFP-transfected HCT119 cells by fluorescence microscopy (Figure 6A) revealed that polyplexes of $10 \%$ and $15 \%$ OCMPEI showed significant transfection efficiency at a w/w ratio of 16 , although lower levels of GFP expression were observed for $5 \%$ and $20 \%$ OCMPEI polyplexes than for either $10 \%$ or $15 \%$ OCMPEI polyplexes. This might be attributable to the low condensation activity of $5 \%$ OCMPEI and the relatively high cytotoxicity of $20 \%$ OCMPEI. In addition, the transfection efficiency of free OCMCh was poor, as was that of free bPEI, notwithstanding its very high capacity to bind DNA at a low w/w ratio. In particular, almost all cells transfected with free bPEI polyplexes were dead. Investigation of the efficiency of gene transfections with the luciferase gene in HEK293, HCT119, and Lovo cells at various weight ratios (Figure 6B) generated results similar to those seen with GFP expression. Many reports suggest that the higher transfection efficiency of polyplexes that include nucleic acids might be attributed to the higher buffering capacity of these complexes and rapid unpackaging of nucleic acids from polymers when they are transfected into the cells. ${ }^{29,39,40}$ As described in the above results, OCMPEI copolymers permitted easy unpackaging ability, which might account for their capacity for high rates of transfection.

\section{siRNA condensation of OCMPEI copolymers}

We anticipated that OCMPEI copolymers might be well suited to delivery of siRNA, given that the chitosan and PEI used have a low molecular weight and assume a branched structure, respectively. Therefore, to investigate the capacity of synthetic copolymers to bind siRNA, copolymers were mixed with GFP-siRNA to allow then to assemble polyplexes at various weight ratios via electrostatic interaction. Figure 7A shows the gel retardation results of siRNA/ OCMPEI polyplexes with increasing weight ratios. All polyplexes migrated at a siRNA-OCMPEI weight ratio of $1: 2$. The $15 \%$ and $20 \%$ siRNA/OCMPEI showed complete 
A
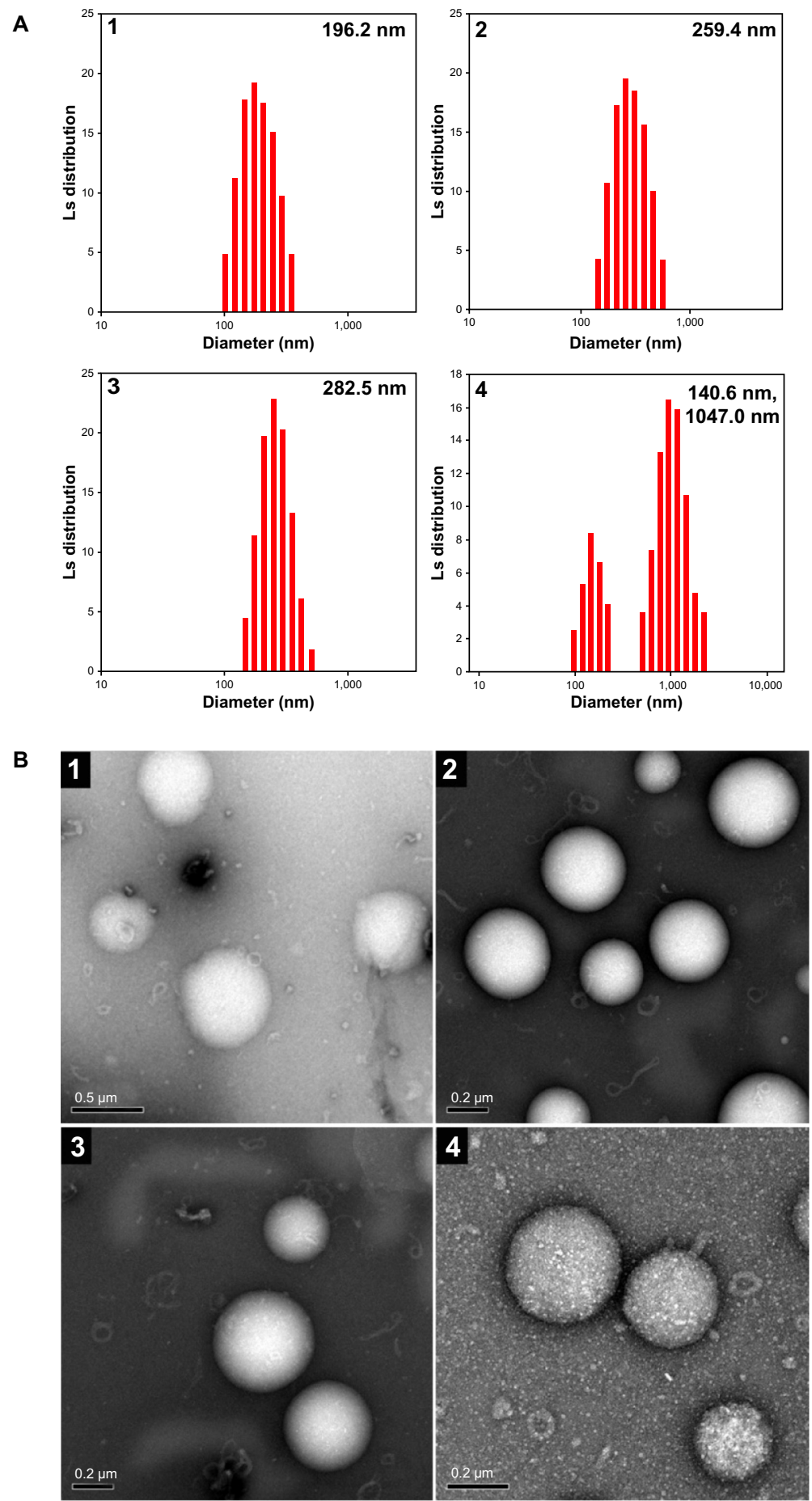

Figure 4 Particle size and morphological observation of pDNA/OCMPEl polyplexes.

Notes: (A) pDNA was complexed with OCMPEI 5\% (I), I0\% (2), 15\% (3), and 20\% (4) at a w/w ratio of I6 and analyzed by DLS. (B) Spherical forms of pDNA/OCMPEI polyplexes were observed by using transmission electron microscope; (I-4) are the same percentages as in (A).

Abbreviations: DLS, dynamic light scattering; OCMPEI, O-carboxymethyl chitosan-graft-branched polyethylenimine; pDNA, plasmid deoxyribonucleic acid.

retardation upon electrophoresis, and their particle sizes varied from $\sim 10-25 \mathrm{~nm}$ at a w/w of 1:16 (Figure 7B). Polyplexes with siRNA were remarkably smaller than those with pDNA, given the difference in the molecular weights of siRNA and pDNA.

\section{In vitro siRNA delivery}

Fluorescence microscopy analysis was performed using PI-labeled siRNA-OCMPEIs to investigate the cellular uptake and distribution of siRNA/OCMPEI polyplexes. HCT 119 cells were treated with siRNA/bPEI or siRNA/OCMPEIs 


\section{A}

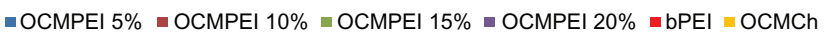

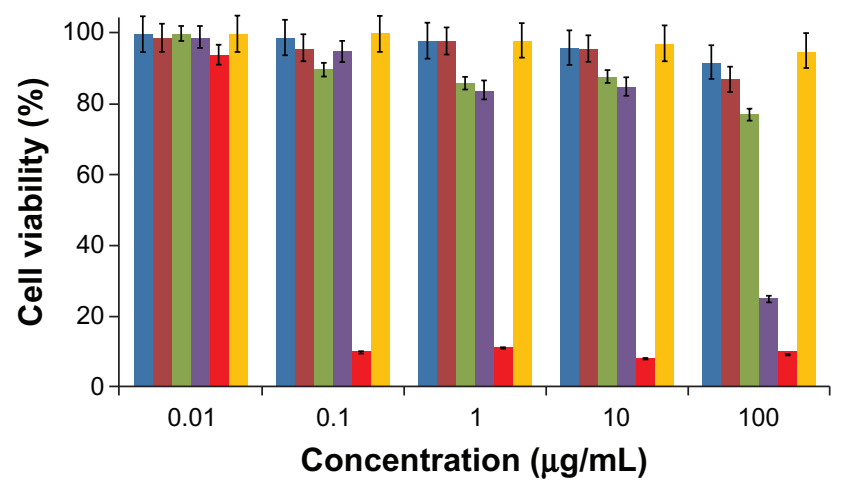

B

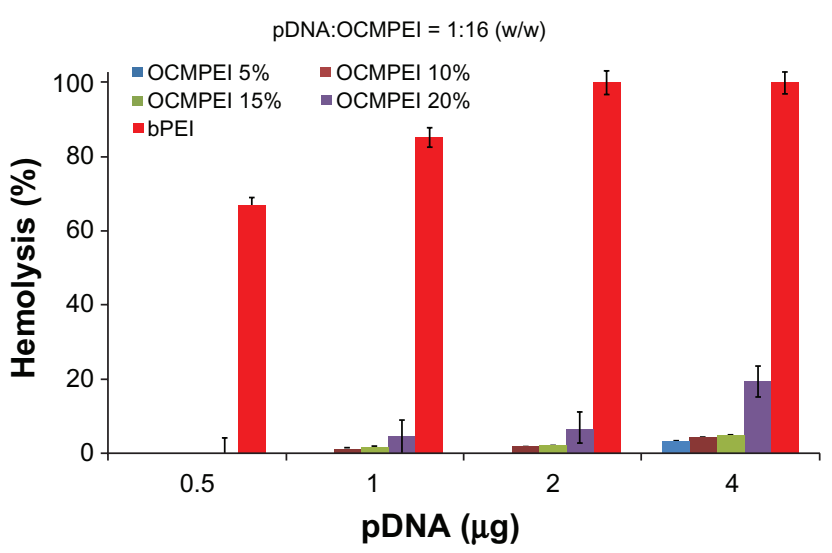

Figure 5 Cytotoxicity of copolymers and hemolytic effect of polyplexes with pDNA against HEK293 (A) and human erythrocytes (B), respectively. Abbreviations: bPEl, branched polyethylenimine; OCMPEI, O-carboxymethyl chitosan-graft-branched polyethylenimine; pDNA, plasmid deoxyribonucleic acid.
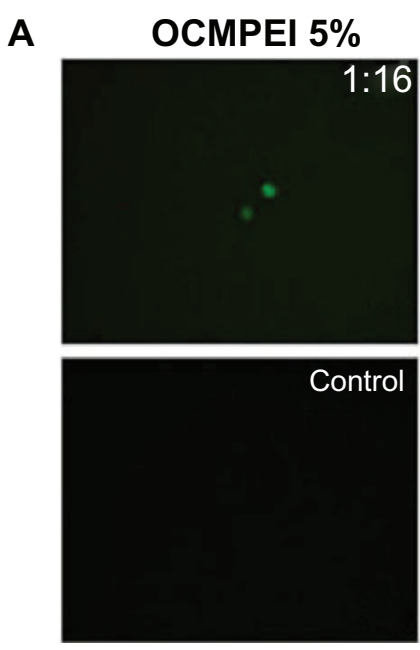

B

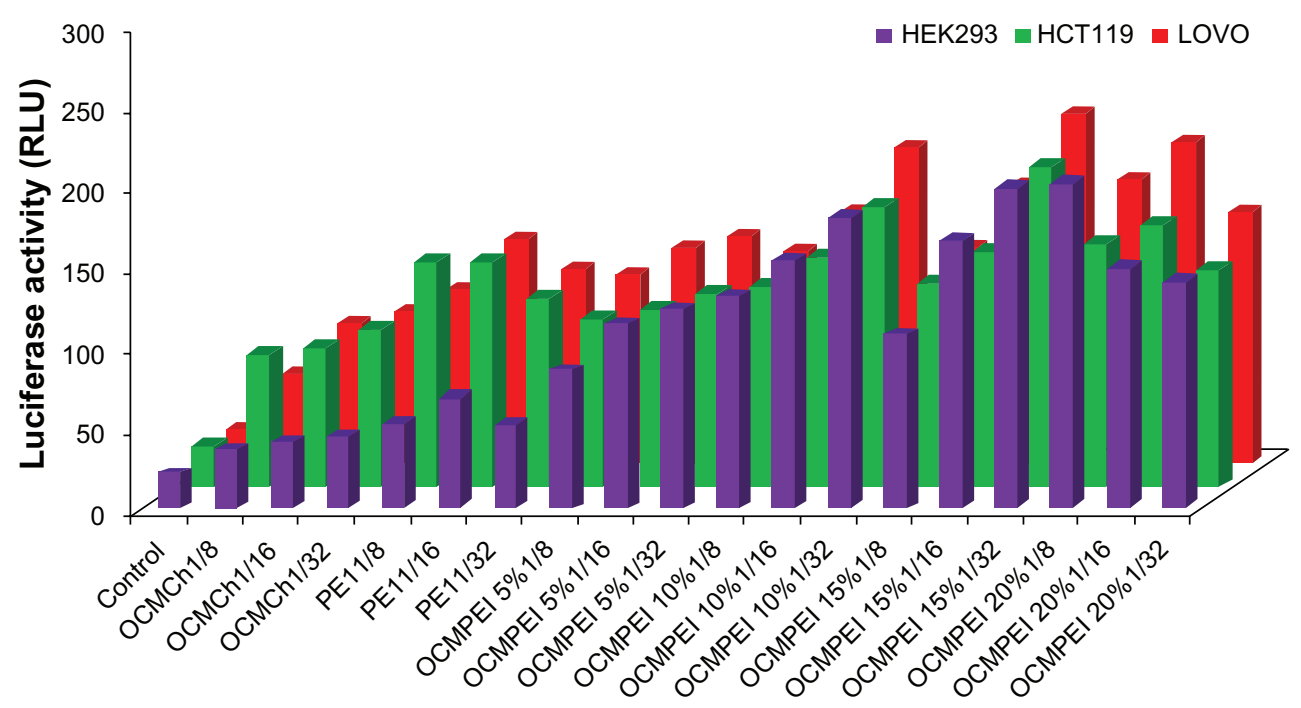

Figure 6 Gene transfection efficiency of pDNA/OCMPEI polyplexes in various cells.

Notes: (A) PEGFP gene transfection of polyplexes at a w/w ratio of I6, free OCMCh, free bPEI, and lipofectamine in HCTII 9 cells. (B) Luciferase expression of pGL3 DNA complexes with OCMPEI copolymers, free OCMCh, free bPEI, and lipofectamine in HEK293, HCTII 9, and Lovo cells.

Abbreviations: bPEl, branched polyethylenimine; DNA, deoxyribonucleic acid; OCMCh, O-carboxymethyl chitosan; OCMPEI, O-carboxymethyl chitosan-graft-branched polyethylenimine; pEGFP, plasmid DNA encoding green fluorescent protein. 
A 1

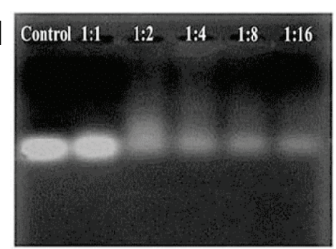

\section{(1)}

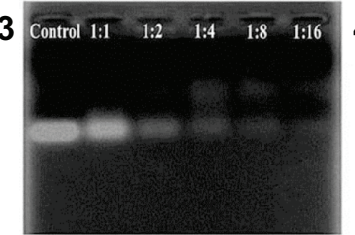

B
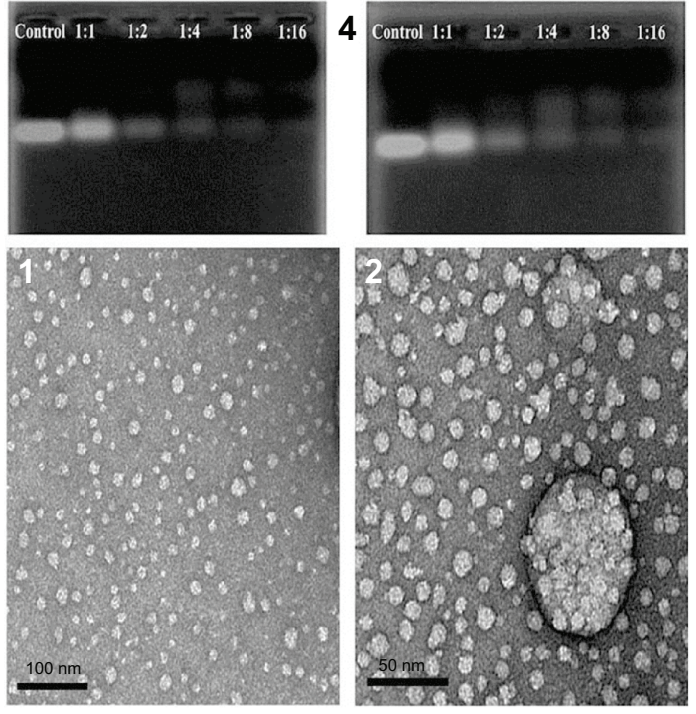

Figure $7 \mathrm{Gel}$ retardation assay and morphological observation of siRNA/OCMPEI polyplexes.

Notes: (A) Electrophoretic mobility of siRNA complexed by (I) OCMPEI 5\%, (2) $10 \%$, (3) $15 \%$, and (4) $20 \%$ at $w / w$ ratios of $1: 1 \sim 1: 16$. (B) morphological observation of siRNA/OCMPEI $10 \%$ and $15 \%$ at a w/w ratio of $1: 8$ using TEM.

Abbreviations: OCMPEI, O-carboxymethyl chitosan-graft-branched polyethylenimine; siRNA, small interfering ribonucleic acid;TEM, transmission electron microscopy. for up to 1 hour (Figure S2). A failure to observe cellular uptake of free PI-labeled siRNA suggested that siRNA was successfully labeled by PI dye (Figure S2, PI dye). Almost all cells transfected with free bPEI were dead, and the apparent distribution of the free bPEI throughout the cell suggested that it had a harmful effect. However, both siRNA/OCMPEIs were effectively delivered to the cytoplasm without cellular damage.

In order to investigate the gene silencing efficiency of siRNA/OCMPEI polyplexes, HCT119 cells that were previously transfected with $\mathrm{pEGFP/OCMPEI}$ and stably expressed GFP were transfected with the $10 \%$ and $15 \%$ GFP-siRNA/OCMPEI complexes. The transfection efficiency of the polyplexes was analyzed by fluorescence microscopy and Western blot analysis using anti-GFP antibody. As shown in Figure 8A, control cells without siRNA expressed high levels of GFP, indicating successful and stable GFP expression through pretransfection with pEGFP. Scrambled siRNA had no effect on silencing GFP expression following transfection under the same conditions, with similar levels of GFP to those found in control cells. Interestingly, cells transfected with GFP-siRNA/ OCMPEI polyplexes showed a significant downregulation of GFP expression compared with control cells. Moreover, siRNA reduced GFP expression in a dose-dependent

A

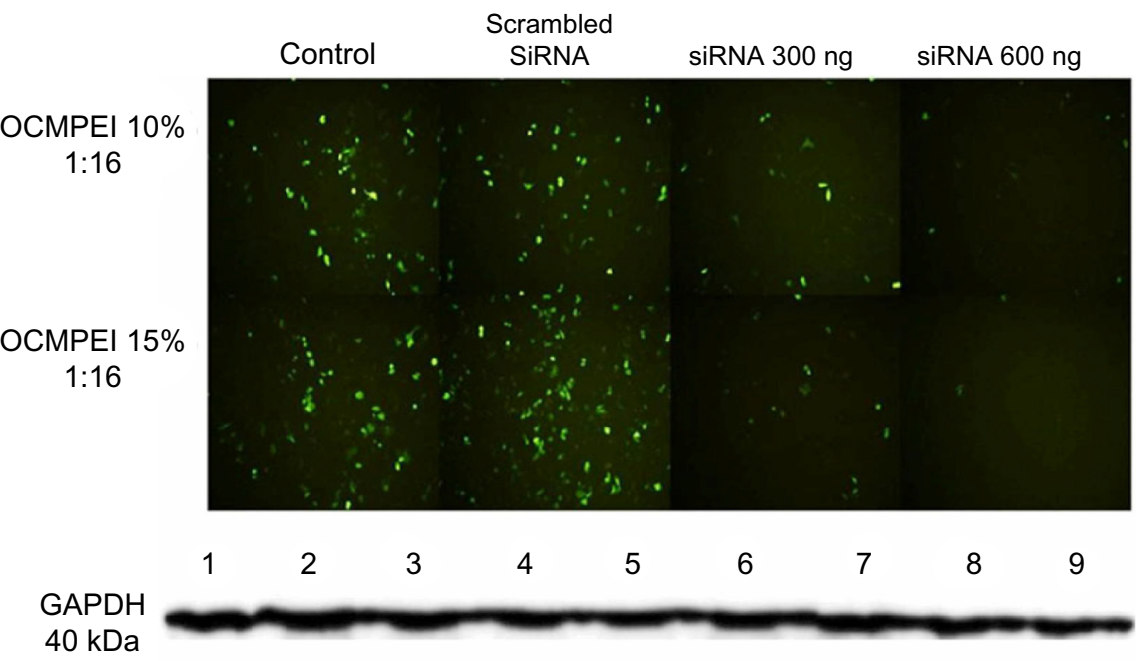

GFP

$26 \mathrm{kDa}$

Figure 8 Gene silencing efficiency of siRNA/OCMPEI 10\% and I5\% polyplexes in HCT II 9 cells.

Notes: (A) HCT I 9 cells pretreated with pEGFP/OCMPEI were transfected with scrambled siRNA (600 ng) or GFP-siRNA (300 ng or 600 ng)/OCMPEI I0\% and I5\%. After 2 days, GFP gene silencing was observed by fluorescence microscope. (B) Western blotting analysis of GFP downregulation. Lane I: control without pEGFP; lane 2: pretreated with pEGFP/OCMPEI 10\%; lane 3: scrambled siRNA/OCMPEI 10\%; lane 4: GFP-siRNA/OCMPEI I0\% (300 ng); lane 5: GFP-siRNA/OCMPEI I0\% (600 ng); lane 6: pretreated with pEGFP/OCMPEI 15\%; lane 7: scrambled siRNA/OCMPEI 15\%; lane 8: GFP-siRNA/OCMPEI I5\% (600 ng), lane 9: GFP-siRNA/OCMPEI I5\% (600 ng).

Abbreviations: OCMPEI, O-carboxymethyl chitosan-graft-branched polyethylenimine; siRNA, small interfering ribonucleic acid; GAPDH, glyceraldehyde 3-phosphate dehydrogenase; pEGFP, plasmid DNA encoding green fluorescent protein; GFP, green fluorescent protein. 
A

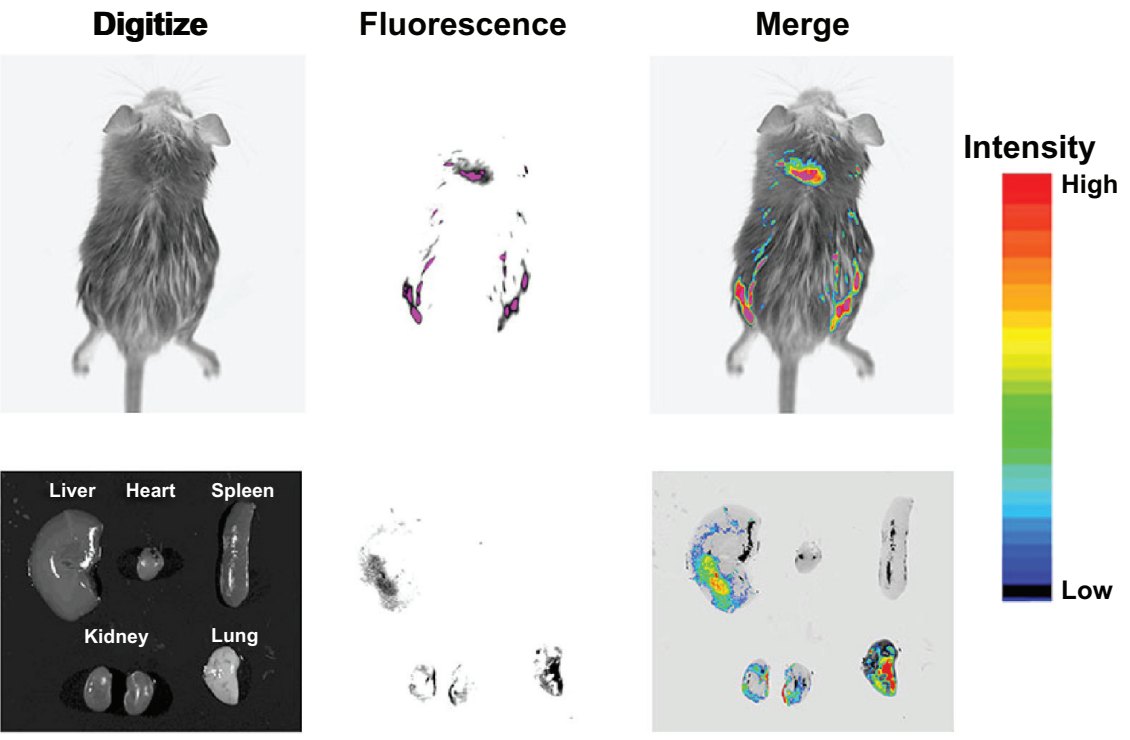

Figure 9 In vivo gene delivery of intravenous injected pEGFP/OCMPEI polyplexes to an ICR mouse.

Notes: OCMPEI I5\% complexed with $30 \mu \mathrm{g}$ of pEGFP at a w/w of 32:I was injected through the mouse tail vein; after 5 days, the whole body (A) and vital organs (B) were fluorescently imaged.

Abbreviations: OCMPEI, O-carboxymethyl chitosan-graft-branched polyethylenimine; pEGFP, plasmid DNA encoding green fluorescent protein

A

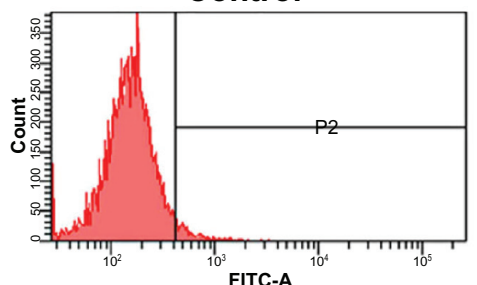

Colchicine
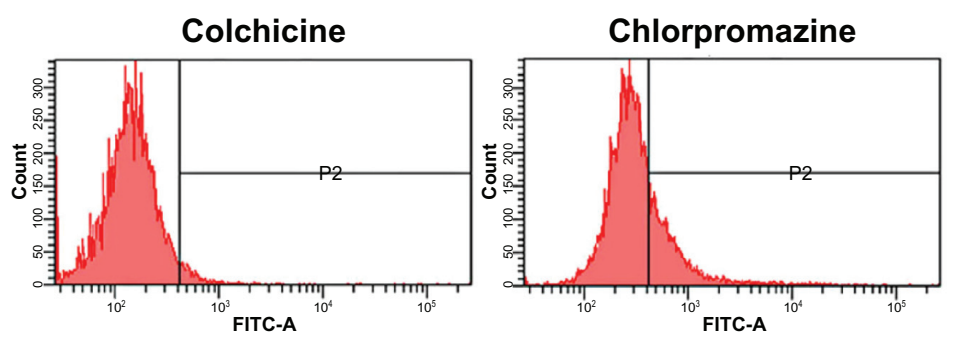

Sodium azide
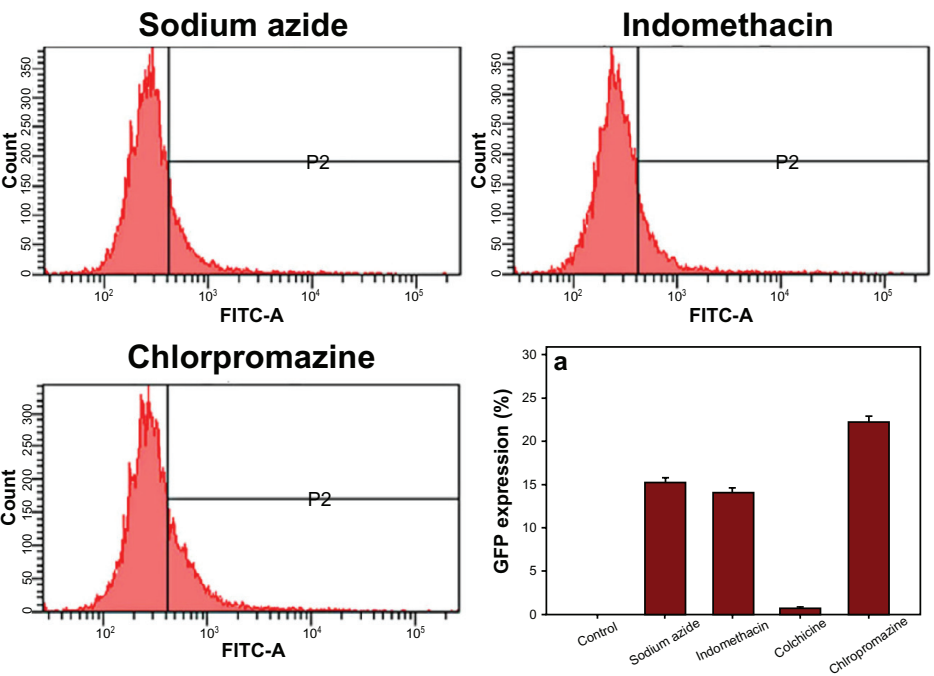

B

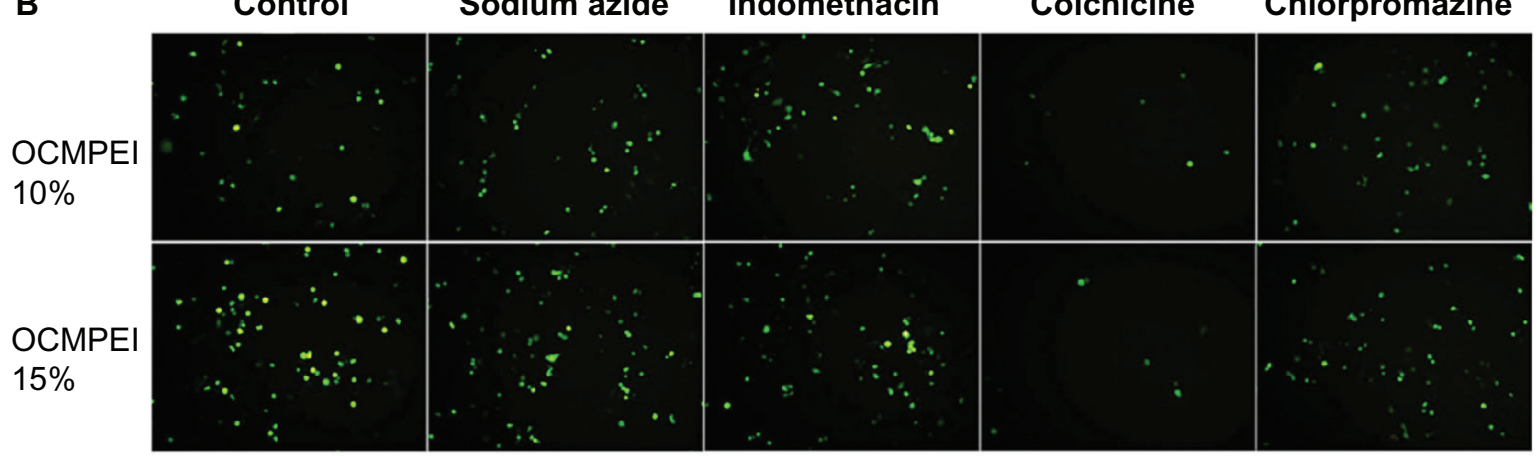

Sodium azide

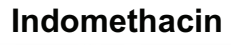

Colchicine

Chlorpromazine

Figure 10 Effect of endocytic inhibitors on cellular uptake in HCTI 9 cells treated with pDNA/OCMPEI polyplexes.

Notes: (A) After I-hour preincubation of endocytic inhibitors $(3 \mu \mathrm{g} / \mathrm{mL}$ sodium azide, $10 \mu \mathrm{g} / \mathrm{mL}$ chlorpromazine, $8 \mu \mathrm{g} / \mathrm{mL}$ colchicine, and $6 \mu \mathrm{g} / \mathrm{mL}$ indomethacin) with HCTI I 9 cells, PEGFP/OCMPEI I0\% was transfected, after which the cell was analyzed by FACSCalibur flow cytometer. (B) The results were visualized using fluorescence microscopy. Abbreviations: FITC-A, fluorescein isothiocyanate A; OCMPEI, O-carboxymethyl chitosan-graft-branched polyethylenimine; pDNA, plasmid deoxyribonucleic acid. 
manner. These results are consistent with immunoblot data for cellular GFP (Figure 8B). Gene silencing by $15 \%$ GFP-siRNA-OCMPEI was more effective than that by $10 \%$ GFP-siRNA-OCMPEI.

\section{In vivo analysis of transfection efficiency}

Gene expression was analyzed in vivo to investigate the possibility of the use of OCMPEI as a carrier for gene delivery. Analysis of GFP expression in a mouse that was intravenously injected with free pEGFP did not show any biodistribution to any of the organs (data not shown), but a mouse injected with pEGFP/OCMPEI showed excellent GFP expression in the lung, kidney, and liver (Figure 9). We propose that an optimized OCMPEI copolymer in this study can be used for in vivo applications. Moreover, gene delivery into specific diseased tissues or cells might be possible if an appropriate targeting moiety is added to surface of the polyplexes.

\section{Mechanism of cellular uptake of pDNA/OCMPEI polyplexes}

Given that polymeric gene delivery was accomplished by endocytic pathways, the mechanism of internalization of the pDNA-OCMPEI polyplexes was investigated using specific endocytic inhibitors. Sodium azide, indomethacin, colchicine, and chlorpromazine inhibit energy-dependent endocytosis, caveolae-mediated endocytosis, microtubuledependent macropinocytosis, and clathrin-mediated endocytosis, respectively. As shown in Figure 10, gene delivery was significantly inhibited by colchicine, suggesting that pDNA uptake via OCMPEI copolymers was achieved by macropinocytosis.

\section{Conclusion}

In the present study, bPEI was conjugated to the carboxyl groups of OCMCh, which was derived from the LMWSC (OCMPEI). This conjugation, which proceeded without the loss of amine groups or excess carboxyl groups from chitosan, improved the solubility and binding capacity of OCMCh, as well as its capacity to release a pDNA or siRNA cargo. The use of OCMPEI copolymers not only enhanced transfection efficiency but also reduced cytotoxicity. Moreover, OCMPEI copolymers provide a delivery system that enables the transfection of pDNA and siRNA into cells either separately or simultaneously. The option to deliver pDNA and siRNA either separately or together might have important therapeutic implications. Our in vivo transfection analysis showed that this copolymer might emerge as a valuable polymeric vector for gene delivery.

\section{Acknowledgment}

This research was supported by the Basic Science Research Program through the National Research Foundation of Korea (NRF) funded by the Ministry of Education, Science and Technology (2011-0012039).

\section{Disclosure}

The authors report no conflicts of interest in this work.

\section{References}

1. Rekha MR, Sharma CP. Polymers for gene delivery: current status and future perspectives. Recent Pat DNA Gene Seq. 2012;6(2): 98-107.

2. Tiera MJ, Shi Q, Winnik FM, Fernandes JC. Polycation-based gene therapy: current knowledge and new perspectives. Curr Gene Ther. 2011;11(4):288-306.

3. Sun X, Zhang N. Cationic polymer optimization for efficient gene delivery. Mini Rev Med Chem. 2010;10(2):108-125.

4. Sunshine JC, Bishop CJ, Green JJ. Advances in polymeric and inorganic vectors for nonviral nucleic acid delivery. Ther Deliv. 2011;2(4): 493-521.

5. Guo X, Huang L. Recent advances in nonviral vectors for gene delivery. Acc Chem Res. 2012;45(7):971-979.

6. Tros de llarduya C, Sun Y, Düzgüneş N. Gene delivery by lipoplexes and polyplexes. Eur J Pharm Sci. 2010;40(3):159-170.

7. Wasungu L, Hoekstra D. Cationic lipids, lipoplexes and intracellular delivery of genes. J Control Release. 2006;116(2):255-264.

8. Zhang JS, Liu F, Huang L. Implications of pharmacokinetic behavior of lipoplex for its inflammatory toxicity. Adv Drug Deliv Rev. 2005;57(5):689-698.

9. Dass CR. Cytotoxicity issues pertinent to lipoplex-mediated gene therapy in-vivo. J Pharm Pharmacol. 2002;54(5):593-601.

10. Midoux P, Breuzard G, Gomez JP, Pichon C. Polymer-based gene delivery: a current review on the uptake and intracellular trafficking of polyplexes. Curr Gene Ther. 2008;8(5):335-352.

11. Jere D, Jiang HL, Arote R, et al. Degradable polyethylenimines as DNA and small interfering RNA carriers. Expert Opin Drug Deliv. 2009;6(8):827-834.

12. Rudzinski WE, Aminabhavi TM. Chitosan as a carrier for targeted delivery of small interfering RNA. Int J Pharm. 2010;399(1-2):1-11.

13. Mao S, Sun W, Kissel T. Chitosan-based formulations for delivery of DNA and siRNA. Adv Drug Deliv Rev. 2010;62(1):12-27.

14. Creusat G, Rinaldi AS, Weiss E, et al. Proton sponge trick for $p H-$ sensitive disassembly of polyethylenimine-based siRNA delivery systems. Bioconjug Chem. 2010;21(5):994-1002.

15. Vicennati P, Giuliano A, Ortaggi G, Masotti A. Polyethylenimine in medical chemistry. Curr Med Chem. 2008;15(27):2826-2839.

16. Kwok A, Hart SL. Comparative structural and functional studies of nanoparticle formulations for DNA and siRNA delivery. Nanomedicine. 2011;7(2):210-219.

17. Hanzlíková M, Soininen P, Lampela P, Männistö PT, Raasmaja A. The role of PEI structure and size in the PEI/liposome-mediated synergism of gene transfection. Plasmid. 2009;61(1):15-21.

18. Kawakami S, Ito Y, Charoensit P, Yamashita F, Hashida M. Evaluation of proinflammatory cytokine production induced by linear and branched polyethylenimine/plasmid DNA complexes in mice. J Pharmacol Exp Ther. 2006;317(3):1382-1390.

19. Garcia-Fuentes M, Alonso MJ. Chitosan-based drug nanocarriers: where do we stand? J Control Release. 2012;161(2):496-504.

20. Bernkop-Schnürch A, Dünnhaupt S. Chitosan-based drug delivery systems. Eur J Pharm Biopharm. 2012;81(3):463-469.

21. Wang JJ, Zeng ZW, Xiao RZ, et al. Recent advances of chitosan nanoparticles as drug carriers. Int J Nanomedicine. 2011;6:765-774. 
22. Casettari L, Vllasaliu D, Lam JK, Soliman M, Illum L. Biomedical applications of amino acid-modified chitosans: a review. Biomaterials. 2012;33(30):7565-7583.

23. Kim IY, Seo SJ, Moon HS, et al. Chitosan and its derivatives for tissue engineering applications. Biotechnol Adv. 2008;26(1):1-21.

24. Zakhem E, Raghavan S, Gilmont RR, Bitar KN. Chitosan-based scaffolds for the support of smooth muscle constructs in intestinal tissue engineering. Biomaterials. 2012;33(19):4810-4817.

25. Jarmila V, Vavríková E. Chitosan derivatives with antimicrobial, antitumour and antioxidant activities - a review. Curr Pharm Des. 2011;17(32):3596-3607.

26. Park SC, Nah JW, Park Y. pH-dependent mode of antibacterial actions of low molecular weight water-soluble chitosan (LMWSC) against various pathogens. Macromol Res. 2011;19(8):853-860.

27. Gao J, Liu R, Wu J, et al. The use of chitosan based hydrogel for enhancing the therapeutic benefits of adipose-derived MSCs for acute kidney injury. Biomaterials. 2012;33(14):3673-3681.

28. Maloy SF, Martin GL, Atanassov P, Cooney MJ. Controlled deposition of structured polymer films: chemical and rheological factors in chitosan film formation. Langmuir. 2012;28(5):2589-2595.

29. Tripathi SK, Goyal R, Kashyap MP, et al. Depolymerized chitosans functionalized with bPEI as carriers of nucleic acids and tuftsin-tethered conjugate for macrophage targeting. Biomaterials. 2012;33(16): 4204-4219.

30. Tripathi SK, Goyal R, Kumar P, Gupta KC. Linear polyethyleniminegraft-chitosan copolymers as efficient DNA/siRNA delivery vectors in vitro and in vivo. Nanomedicine. 2012;8(3):337-345.

31. Huh MS, Lee SY, Park S, et al. Tumor-homing glycol chitosan/ polyethylenimine nanoparticles for the systemic delivery of siRNA in tumor-bearing mice. J Control Release. 2010;144(2):134-143.
32. Jiang HL, Kim YK, Arote R, et al. Mannosylated chitosan-graftpolyethylenimine as a gene carrier for Raw 264.7 cell targeting. Int $J$ Pharm. 2009;375(1-2):133-139.

33. Jiang HL, Kwon JT, Kim EM, et al. Galactosylated poly(ethylene glycol)-chitosan-graft-polyethylenimine as a gene carrier for hepatocyte-targeting. J Control Release. 2008;131(2):150-157.

34. Lou YL, Peng YS, Chen BH, Wang LF, Leong KW. Poly(ethylene imine)-g-chitosan using EX-810 as a spacer for nonviral gene delivery vectors. J Biomed Mater Res A. 2009;88(4):1058-1068.

35. Nah JW, Jang MK. Spectroscopic characterization and preparation of low molecular, water-soluble chitosan with free-amine group by novel method. J Polym Sci Part A: Polym Chem. 2002;40(21): 3796-3803.

36. Xu T, Xin M, Li M, Huang H, Zhou S, Liu J. Synthesis, characterization, and antibacterial activity of N,O-quaternary ammonium chitosan. Carbohydr Res. 2011;346(15):2445-2450.

37. Lavertu M, Méthot S, Tran-Khanh N, Buschmann MD. High efficiency gene transfer using chitosan/DNA nanoparticles with specific combinations of molecular weight and degree of deacetylation. Biomaterials. 2006;27(27):4815-4824.

38. MacLaughlin FC, Mumper RJ, Wang J, et al. Chitosan and depolymerized chitosan oligomers as condensing carriers for in vivo plasmid delivery. J Control Release. 1998;56(1-3):259-272.

39. Goyal R, Tripathi SK, Tyagi S, et al. Linear PEI nanoparticles: efficient pDNA/siRNA carriers in vitro and in vivo. Nanomedicine. 2012;8(2):167-175.

40. Ren Y, Jiang X, Pan D, Mao HQ. Charge density and molecular weight of polyphosphoramidate gene carrier are key parameters influencing its DNA compaction ability and transfection efficiency. Biomacromolecules. 2010;11(12):3432-3439. 


\section{Supplementary figures}

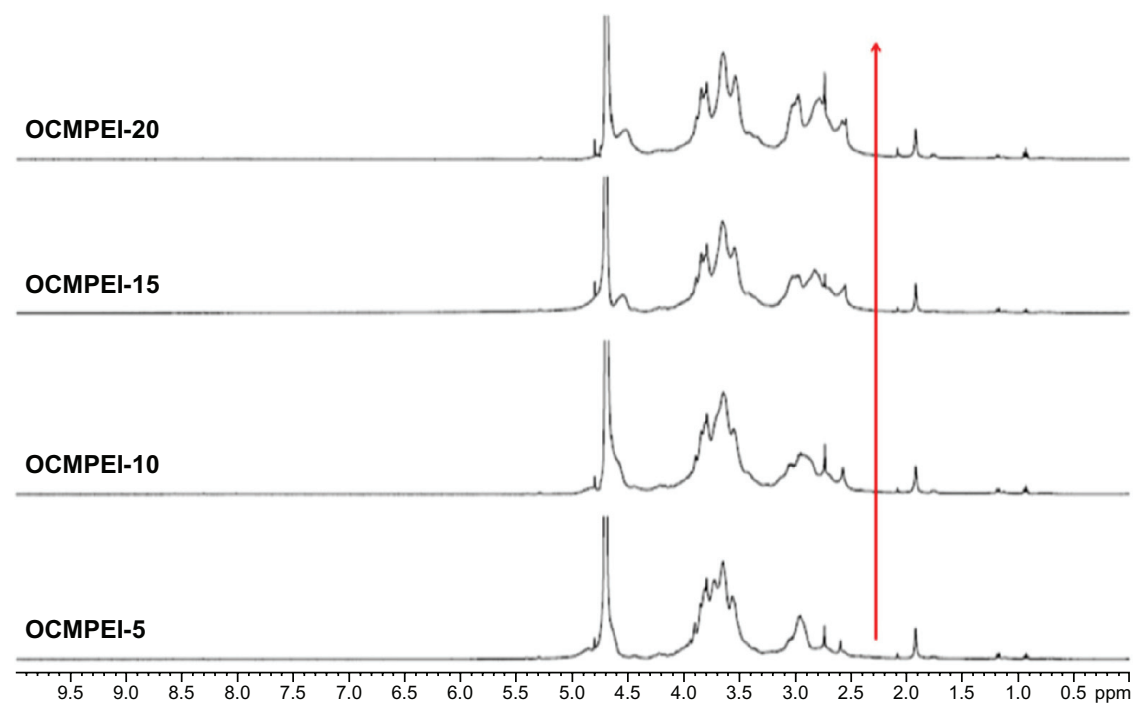

Figure SI 'H NMR of OCMPEI $5 \%, 10 \%, 15 \%$, and $15 \%$ in $\mathrm{D}_{2} \mathrm{O}$ solvent.

Note: The red arrow indicates the increasing intensity peak of PEI.

Abbreviations: $\mathrm{D}_{2} \mathrm{O}$, deuterium oxide; 'H NMR, ' $\mathrm{H}$ nuclear magnetic resonance; OCMPEl, O-carboxymethyl chitosan-graft-branched polyethylenimine.

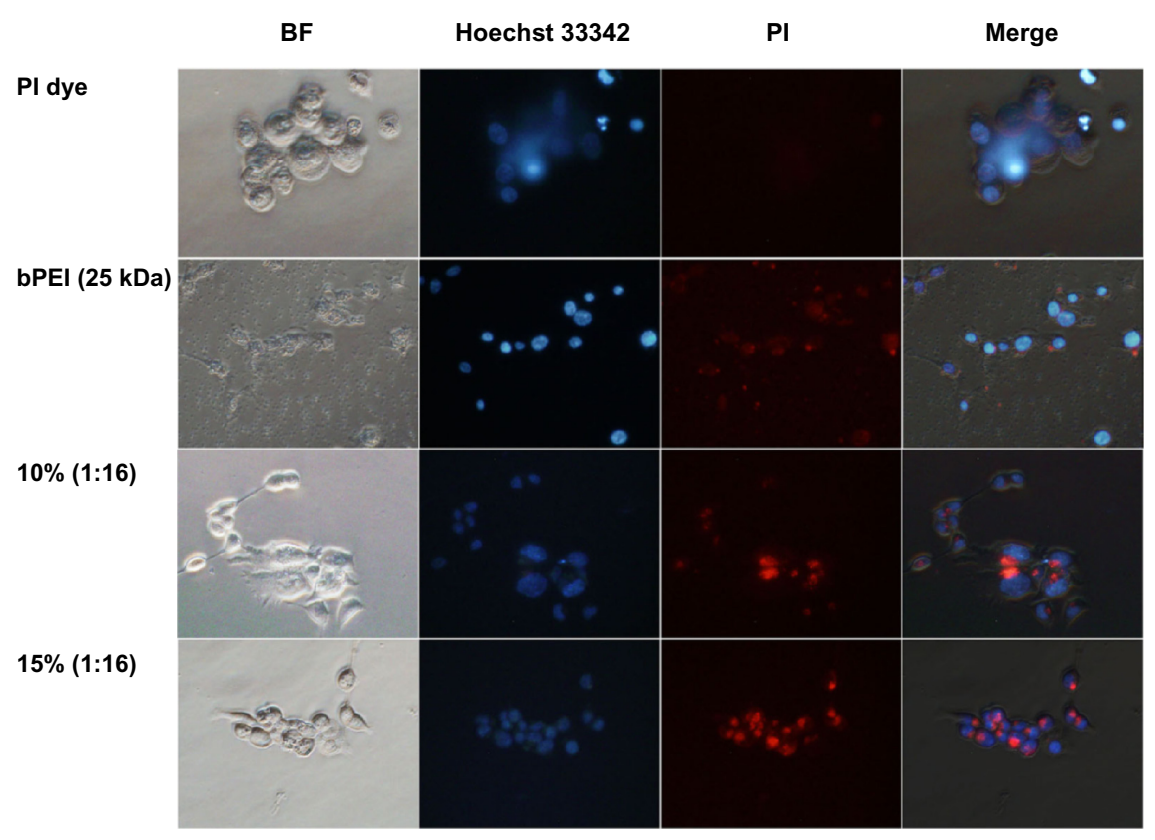

Figure S2 Cellular uptake of PI-labeled siRNA/OCMPEI polyplexes in HCT I 9 cells.

Note: PI-labeled siRNA was complexed with OCMPEI 10\% and I5\% at a w/w ratio of I:16 and cell nuclei were stained by Hoechst 33342 .

Abbreviations: BF, bright field; OCMPEl, O-carboxymethyl chitosan-graft-branched polyethylenimine; PI, propidium iodide; siRNA, small interfering ribonucleic acid; bPEl, branched polyethylenimine.

International Journal of Nanomedicine

\section{Publish your work in this journal}

The International Journal of Nanomedicine is an international, peerreviewed journal focusing on the application of nanotechnology in diagnostics, therapeutics, and drug delivery systems throughou the biomedical field. This journal is indexed on PubMed Central,

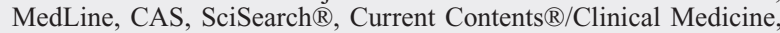

Journal Citation Reports/Science Edition, EMBase, Scopus and the Elsevier Bibliographic databases. The manuscript management system is completely online and includes a very quick and fair peer-review system, which is all easy to use. Visit http://www.dovepress.com/ testimonials.php to read real quotes from published authors.

\footnotetext{
Submit your manuscript here: http://www.dovepress.com/international-journal-of-nanomedicine-journal
} 